\title{
Comparison of esophageal placement of Bravo capsule system under direct endoscopic guidance with conventional placement method
}

This article was published in the following Dove Press journal:

Clinical and Experimental Gastroenterology

14 October 2010

Number of times this article has been viewed

\section{Aijaz A Sofi \\ Charles Filipiak \\ Thomas Sodeman \\ Usman Ahmad \\ Ali Nawras \\ Isam Daboul}

Department of Medicine, Division of Gastroenterology, University of Toledo Medical Center, Toledo, Ohio, USA
Correspondence: Isam Daboul Division of Gastroenterology, Department of Medicine, University of Toledo Medical Center, 3000 Arlington Avenue, Toledo, Ohio 436I4, USA

Tel + I 419383349 |

Fax +I 4I93836197

Email isam.daboul@live.com
Background: Conventional placement of a wireless esophageal $\mathrm{pH}$ monitoring device in the esophagus requires initial endoscopy to determine the distance to the gastroesophageal junction. Blind placement of the capsule by the Bravo delivery system is followed by repeat endoscopy to confirm placement. Alternatively, the capsule can be placed under direct vision during endoscopy. Currently there are no published data comparing the efficiency of one method over the other. The objective of this study was to compare the method of Bravo wireless $\mathrm{pH}$ device placement under direct visualization with the conventional method.

Methods: A retrospective study involving 58 patients (29 patients with indirect and 29 patients with direct visualization) who had Bravo capsule placement. The physician endoscopy procedure notes, nurse's notes, postprocedure notes, recovery notes, and $\mathrm{pH}$ monitoring results were reviewed. The safety of the procedures, length of the procedures, and patient tolerability were evaluated.

Results: None of the 58 patients had early detachment of the device and had no immediate procedure-related complications. The overall incidence of complications in both the groups was similar. No failures due to the technique were noted in either group. Average amount of time taken for the procedure was similar in both groups.

Conclusion: The technique of placing a Bravo $\mathrm{pH}$ device under direct visualization is as safe and effective as the conventional method. In addition, there is an added advantage of avoiding a second endoscopic intubation in the direct visualization technique.

Keywords: Bravo capsule, technique, esophageal $\mathrm{pH}$ monitoring

\section{Introduction}

Esophageal $\mathrm{pH}$ monitoring is an essential investigation in patients with suspected gastroesophageal reflux disease (GERD) with refractory symptoms and in patients who are considered for antireflux surgery in the absence of endoscopic changes of GERD. ${ }^{1}$ It is also utilized for evaluation of patients with extraesophageal manifestations of GERD. Esophageal $\mathrm{pH}$ monitoring was traditionally performed by passing a catheter with a $\mathrm{pH}$ electrode transnasally and positioning the electrode $5 \mathrm{~cm}$ above the upper border of the lower esophageal sphincter. There were several drawbacks with the conventional method of testing, which include nose and throat discomfort, dysphagia, and nasal discharge, as a result of the catheter passing through the nose and throat into the lower esophagus. In the majority of cases, the patient is unable to perform daily activities with these catheters in place. ${ }^{2}$ Furthermore, the $\mathrm{pH}$ probe could potentially become displaced with changing body position, talking, or swallowing, which could alter the study results. ${ }^{3}$ 
In recent years, the traditional approach of catheter-based $\mathrm{pH}$ monitoring has been replaced by the wireless $\mathrm{pH}$ monitor, ie, the Bravo ${ }^{\mathrm{TM}} \mathrm{pH}$ testing system (Medtronic Inc., Shoreview, MN). In this system, the Bravo capsule is placed into the esophagus with the assistance of the Bravo delivery system. The conventional ("indirect") method of placing the capsule in the esophagus involves an initial endoscopy to determine the distance from the incisor teeth to the gastroesophageal (GE) junction. The endoscope is then removed and the device is placed blindly using the Bravo delivery system as per the measurements obtained by endoscopy. After placement of the Bravo capsule, the endoscope is reinserted again to confirm its attachment and location. This conventional method is a blind technique and usually requires performing endoscopy twice to confirm the attachment and correct positioning of the capsule in the esophageal wall. ${ }^{4}$

Another technique that has been used for placing the Bravo capsule provides accurate positioning and confirms attachment of the capsule under direct endoscopic visualization. In this technique ("direct" method), the Bravo delivery system is concurrently placed without removing the endoscope and the device is released at a desired location. ${ }^{5}$

Endoscopists have their own arbitrary preference for a particular technique of placing a device. There are no studies to compare the two methods of placing the device in terms of safety, patient tolerability, and reliability of the technique. The objective of this study was to compare the safety, performance, and tolerability of the technique of Bravo wireless $\mathrm{pH}$ device placement under direct endoscopic visualization (direct) with that of the conventional (indirect) technique of capsule placement.

\section{Methods}

After approval by the institutional review board, all patients who had the Bravo capsule placed in the esophagus by either direct visualization or the indirect conventional method were identified. From this patient population, 29 consecutive patients had the Bravo device placed by the direct method over a period of six months, when the endoscopists switched from their practice of placing a device from the indirect to the direct technique. In the control group, 29 patients who had the Bravo device placed by the indirect method were randomly selected. The physician endoscopy procedure notes, nurse's notes, postprocedure notes, recovery notes, and patient questionnaire were all reviewed. Data on $\mathrm{pH}$ results, complications during the procedure, symptoms, and complications during the data recording period, patient tolerability, and degree of satisfaction with the test in both groups were obtained. Data were also obtained on time taken in the procedure. We hypothesized that procedures performed in the evening might take longer than procedures performed in the morning, which could be related to the endoscopist's fatigue towards the evenings. Therefore, in order to minimize the bias, we compared the procedure time of morning procedures and evening procedures.

In addition, data were also obtained on patient experience of the procedure, willingness to repeat the procedure if needed, and number of workdays off following the procedure. Patient experience with the procedure of capsule placement was graded as good, average, and bad, as recorded from the questionnaire given to patients. Patient satisfaction with the test was recorded using a Likert 10-point visual analog scale, with zero signifying very unsatisfactory and 10 very satisfactory. Values of 1-4 were graded as unsatisfactory, values from 5-8 as average, and values of 9 and 10 as very satisfactory. Endoscopists were questioned about their views on the complexity and overall experience with the procedure. Intravenous diazepam was used as a sedative in both the groups. The primary outcome of the study was to compare the safety of the two methods. The secondary outcomes were to evaluate any difference in the time of the procedure, patient tolerability, and operator experience with the two methods. In the direct method of Bravo capsule placement, upper endoscopy was performed to examine the esophagus, stomach, and duodenum, and to identify the squamocolumnar junction. Next, while keeping the endoscope in the esophagus and with the gastroesophageal (GE) junction in view, the Bravo delivery system was inserted orally and passed through the throat alongside the endoscope until it became visualized in the endoscopic field. The measurements on the endoscope and the delivery device were matched. The scope was then withdrawn to $8 \mathrm{~cm}$ above the GE junction and then, under direct view of the delivery system, the Bravo capsule was deployed $6 \mathrm{~cm}$ above the GE junction in the same way as it is done in the conventional technique.

In the conventional (indirect) method, upper endoscopy was performed similarly to examine the duodenum, stomach, and esophagus, and then the distance between the squamocolumnar junction and the incisors was measured. The endoscope was then removed and the Bravo $\mathrm{pH}$ monitoring device was deployed blindly using the Bravo delivery system guided by the measurements obtained from endoscopy. After placement of the Bravo capsule, the endoscope was reinserted to confirm its attachment and location. 


\section{Statistical analysis}

The $t$-test was used for analysis of the length of procedure time. For analysis of time taken in procedures performed before noon and procedures performed in the afternoon, one-way analysis of variance was used. Chi-square analysis was used to analyze all other data. Statistical significance was considered reached when the $P$ value was $<0.05$. The SPSS 16 (SPSS, Chicago, IL) was utilized for all statistical analysis.

\section{Results}

Fifty-eight patients who had Bravo capsule placement by either the direct or indirect method were included in the study. Table 1 shows the baseline characteristics of the patient population in the two groups. All the procedures were performed by two endoscopists (ID and CF). Both endoscopists used either method to place the device. The two groups were similar in terms of age, gender, and underlying diseases. One patient in the direct group and four patients in the indirect group had previously undergone Nissen's fundoplication. There were no early detachments of the device and no prolonged retention of the device in any patient in either group. One of the patients in the "indirect" group had an esophageal stricture and needed dilatation before placement of the Bravo capsule. This patient had also previously undergone Nissen's fundoplication. Postprocedural complications in the two groups are summarized in Table 2. Among the patients who developed chest pain after the procedure, chest pain was severe enough in two patients in the direct group to require patient observation for three and five hours, respectively, before discharge. One of the patients in the indirect group had three attempts at device insertion. The device failed to transmit signals soon after deployment in two patients in the indirect group and in one patient in the direct group. One patient each in both the direct group and indirect group had $\mathrm{pH}$ recording for only 12 hours and

Table I Patient demographics and indication for $\mathrm{pH}$ monitoring

\begin{tabular}{lll}
\hline & $\begin{array}{c}\text { Direct } \\
(\mathbf{n}=\mathbf{2 9})\end{array}$ & $\begin{array}{l}\text { Indirect } \\
(\mathbf{n}=\mathbf{2 9})\end{array}$ \\
\hline Mean age (years, range) & $5 \mathrm{I}(26-80)$ & $46(27-87)$ \\
Sex (M:F) & $9: 20$ & $8: 21$ \\
Indication for PH monitoring & & \\
Intractable symptoms on PPI & $14(48 \%)$ & $10(34 \%)$ \\
Extraesophageal symptoms & $14(48 \%)$ & $12(41 \%)$ \\
Preoperative evaluation & $0(0 \%)$ & $3(10 \%)$ \\
Reflux symptoms after & $\mathrm{I}(3.5 \%)$ & $4(13.7 \%)$ \\
Nissen's procedure & & \\
\hline
\end{tabular}

Abbreviations: PPI, proton pump inhibitor; M, male; F, female.
Table 2 Adverse events in patients in the direct and indirect monitoring groups

\begin{tabular}{llll}
\hline Characteristics & $\begin{array}{l}\text { Direct } \\
\text { group (\%) }\end{array}$ & $\begin{array}{l}\text { Indirect } \\
\text { group (\%) }\end{array}$ & P value \\
\hline Sore throat & $7(24.13 \%)$ & $12(41.37 \%)$ & 0.13 \\
Dysphagia & $9(31.03 \%)$ & $8(27.58 \%)$ & 0.77 \\
Chest pain & $6(20.68 \%)$ & $7(24.13 \%)$ & 0.75 \\
Cough & $4(13.79 \%)$ & $2(6.89 \%)$ & 0.74 \\
Procedural complication & $2(6.89 \%)$ & I (3.44\%) & 0.5 \\
$\begin{array}{l}\text { Patients (n) needing days } \\
\text { off work }\end{array}$ & $6(20.68 \%)$ & $6(20.68 \%)$ & 1 \\
\hline
\end{tabular}

19 hours, respectively. Two patients in the indirect group and one patient in the direct group were scheduled for 24-hour monitoring only. All other patients had two-day monitoring. The average recording time in the two groups was similar (mean 22 hours 51 minutes versus 22 hours 39 minutes for the direct and indirect methods, respectively, on day 1, and 20 hours 31 seconds and 18 hours and 10 seconds on day 2). The mean Demeester score on the first day of recording in the direct and indirect groups was 29.84 (standard deviation, 35.51 ) and 29.9 (34.5), respectively. The Demeester score on the second day of recording was 16.23 (13.6) and 23.1 (33.15) for the direct and indirect groups, respectively. In terms of patient experience and satisfaction with the test, the difference between the two groups was not statistically significant (Table 3). The willingness to repeat the test (if needed) in the two groups was also statistically insignificant. An equal number of patients in the two groups required days off work after the procedure. There was no difference between the time taken for the procedure between the two groups (Table 4). In the view of the endoscopists, there was no difference in the procedure, except for the ease of placement with the direct method.

Table 3 Patient tolerability and experience

\begin{tabular}{llll}
\hline Characteristic & Direct (\%) & Indirect (\%) & P value \\
\hline $\begin{array}{l}\text { Patient experience } \\
\text { Good }\end{array}$ & $10(34 \%)$ & $8(27 \%)$ & 0.82 I \\
Okay & $16(55 \%)$ & $17(58 \%)$ & \\
Bad & $3(10 \%)$ & $4(13 \%)$ & \\
Satisfaction (score) & & & \\
Good (9-10) & $22(76 \%)$ & $18(62 \%)$ & 0.115 \\
Average (5-8) & $3(10 \%)$ & $4(13 \%)$ & \\
Bad (I-4) & $4(13 \%)$ & $8(27 \%)$ & \\
Willingness to repeat & & & \\
the procedure & & & \\
Yes & $26(89 \%)$ & $23(79 \%)$ & 0.094 \\
No & $3(10 \%)$ & $6(20 \%)$ & \\
\hline
\end{tabular}


Table 4 Mean time taken for the direct and indirect method of capsule placement

\begin{tabular}{llll}
\hline & Direct & Indirect & $\boldsymbol{P}$ value \\
\hline $\begin{array}{l}\text { Morning:afternoon procedures }(\mathrm{n}) \\
\begin{array}{l}\text { Average time period for procedure } \\
\text { (minutes) }\end{array}\end{array}$ & $18: 11 \mathrm{I} .44$ & $22: 7$ & \\
$\begin{array}{l}\text { Average time period for morning } \\
\text { procedure (minutes) }\end{array}$ & 14.58 & 13.46 & 0.122 \\
$\begin{array}{l}\text { Average time period for afternoon } \\
\text { procedure (minutes) }\end{array}$ & 14.14 & 13.00 & 0.662 \\
\hline
\end{tabular}

\section{Discussion}

The wireless esophageal $\mathrm{pH}$ monitoring system is a highly tolerable method of investigation available for patients with GERD. Since the introduction of this technology in the $2001,{ }^{7}$ several methods of placement of the capsule in the esophagus have been described. These methods include calculating the site of placement of the device by endoscopy, followed by either transoral ${ }^{4}$ or transnasal $^{8}$ insertion of the capsule delivery system, then placing the device at the site determined by prior calculation. Deployment of the device under direct endoscopic view has also been described..$^{5}$ In addition, nonendoscopic methods of placing the device have been described. ${ }^{9}$ In the nonendoscopic technique of device placement, the position of the lower esophageal sphincter is determined by esophageal manometry, which is then followed by blind deployment of the capsule guided by measurements obtained from manometry. However, the endoscopic method of placing the capsule is most commonly used worldwide. This is because it allows evaluation of the upper gastrointestinal tract for the presence of other concomitant pathologies that would otherwise preclude the use of these devices. ${ }^{10}$ Furthermore, it allows evaluation of the esophagus in patients with GERD. Some authors have suggested using the manometry method in patients who had recent endoscopy without any alarm signs. ${ }^{10}$ This technique could be potentially useful in patients with long-segment Barrett's esophagus where the squamocolumnar junction is no longer the landmark of the lower esophageal sphincter. ${ }^{11}$ However, this technique involves placing the capsule by the transnasal route, which is not well tolerated by patients and poses a risk of significant epistaxis. Using the transoral route for placing the device requires usage of a conversion factor proposed by Lacy et al. ${ }^{6}$ However, this conversion factor has its own limitations; it cannot be used in patients with a hiatal hernia or in patients who are very tall or very short. In view of all these limitations, the endoscopic method of placing the device is currently the most commonly used method.
There have been no studies to date comparing the direct and indirect methods of Bravo capsule placement in the esophagus. Currently, the indirect method is most commonly used for deploying the device in the lower esophagus.

Sore throat was the most common adverse effect reported by our patients $(32.7 \%)$. Postprocedure dysphagia was the second most common adverse event encountered in our patients $(29.3 \%$ of cases). This was comparable with the incidence of dysphagia reported in other studies. ${ }^{6}$ Chest pain was seen in $22.4 \%$ of cases. Chest pain was predominantly reported by patients who complained of dysphagia. Inadequate data reception in five patients (three in the indirect group and two in the direct group) could have potentially occurred due to technical malfunctions with the device, as reported in earlier studies. ${ }^{4,6}$

In theory, the direct method of placing the device would be expected to take less time than the conventional method because the latter technique usually requires repeat endoscopic intubation. However, in our study, we found that the average time taken for the procedure was similar between the two groups. This can be explained by the fact that endoscopists have more experience with the indirect method because it has been used since the introduction of this technology, whereas the direct method of placement was recently started in our hospital. Furthermore, there was no difference in time taken in the procedures performed in the morning compared with procedures performed in the afternoon (Table 4).

In our study, we found that placing the Bravo capsule system under direct visualization is a safe procedure. The safety of this method is comparable with the indirect method given the similar frequency of procedure-related complications seen in the two groups. In addition, the added advantage with the direct method is the avoidance of second-look endoscopy to confirm the site of attachment of the device. The placement of the device by the direct method is precise. This is vital because the device could be wrongly deployed at an undesirable location, including the stomach wall ${ }^{9}$ or oropharynx, ${ }^{12}$ by the indirect method. Therefore, there would be a remote chance of deploying the capsule at an undesirable location with the direct method. Further, the direct method of placing the capsule allows the esophagus to be cleared of air under direct vision, which ensures the successful placement of the device by enhancing the contact between the esophageal wall and the well of the capsule. This is important because early detachment is a well known complication with the Bravo system, and its incidence could be as high as $2 \%-12 \%{ }^{4,13}$ 
In our study, we found that patient experience with the procedure was similar (75.9\% versus $66.06 \%$, respectively) in the direct group and indirect group. Patient satisfaction with the test was similar ( $34.4 \%$ versus $27.5 \%$ ) between the direct and indirect groups. Patient willingness to repeat the test, if necessary, was also similar between the two groups ( $89.7 \%$ versus $75.5 \%)$. The explanation for the small observed difference, although not statistically significant, could be the fact that in the "indirect" group patients had to undergo endoscopy twice in the same sitting. This could be more uncomfortable than undergoing single endoscopy. For the endoscopist, the direct method may be preferable because it avoids performing endoscopy twice in the same patient.

Our study had a few limitations. Firstly, it is retrospective by design. Secondly, the small sample size of the study groups cannot rule out the possibility of Type II error with regard to safety and patient experience with the procedure. Nonetheless, the results of this study suggest an advantage of the direct method over the conventional (indirect) method of placement of Bravo capsule system.

\section{Conclusion}

The direct method of deploying the wireless $\mathrm{pH}$ monitoring device is safe and effective. Patient tolerance, acceptance, and the length of procedure time were similar to that of the indirect method. There is an additional advantage of avoiding a second endoscopy in the direct group, although there is no difference in the length of procedure time between these two techniques. However, a larger prospective study is needed to provide more information regarding complications and adverse events with these two methods of capsule placement.

\section{Disclosure}

This research was not funded by any source. The authors report no conflicts of interest in this work.

\section{References}

1. Kahrilas PJ, Shaheen NJ, Vaezi MF, et al. American Gastroenterological Association Medical Position Statement on the management of gastroesophageal reflux disease. Gastroenterology. 2008;135(4):1383-1391.

2. Mearin F, Balboa A, Dot J, et al. How standard is a standard day during a standard ambulatory 24-hour esophageal $\mathrm{pH}$ monitoring? Scand J Gastroenterol. 1998;33(6):583-585.

3. Aksglaede K, Funch-Jensen P, Thommesen P. Intra-esophageal pH probe movement during eating and talking. A videoradiographic study. Acta Radiol. 2003;44(2):131-135.

4. Pandolfino JE, Richter JE, Ours T, et al. Ambulatory esophageal pH monitoring using a wireless system. Am J Gastroenterol. 2003;98(4): $740-749$.

5. Wenner J, Johnsson F, Johansson J, et al. Wireless oesophageal $\mathrm{pH}$ monitoring: Feasibility, safety and normal values in healthy subjects. Scand J Gastroenterol. 2005;40(7):768-774.

6. Lacy BE, O'Shana T, Hynes M, et al. Safety and tolerability of transoral Bravo capsule placement after transnasal manometry using a validated conversion factor. Am J Gastroenterol. 2007;102(1):24-32.

7. Streets CG, DeMeester TR, Peters JH, et al. Clinical evaluation of Bravo $^{\mathrm{TM}}$ probe-a catheter-free ambulatory esophageal $\mathrm{pH}$ monitoring system. Gastroenterology. 2001;120 (5 Suppl 1):A35.

8. Belafsky PC, Allen K, Castro-Del Rosario L, et al. Wireless $\mathrm{pH}$ testing as an adjunct to unsedated transnasal esophagoscopy: The safety and efficacy of transnasal telemetry capsule placement. Otolaryngol Head Neck Surg. 2004;131(1):26-28.

9. Marchese M, Spada C, Iacopini F, et al. Nonendoscopic transnasal placement of a wireless capsule for esophageal $\mathrm{pH}$ monitoring: Feasibility, safety, and efficacy of a manometry-guided procedure. Endoscopy. 2006;38(8):813-818.

10. Marchese M, Spada C, Costamagna G. Bravo capsule for wireless 48-h pH monitoring: Proposed algorithm for its placement. Am J Gastroenterol. 2007;102(9):2104-2105.

11. Kwiatek MA, Pandolfino JE. The Bravo $\mathrm{pH}$ capsule system. Dig Liver Dis. 2008;40(3):156-160.

12. Elias G, Charbel H, Gupta N, et al. S1927: A safer way of placement of the wireless esophageal $\mathrm{pH}$ monitoring Bravo capsule. Gastroenterology. 2009;136 (5 Suppl 1):A294.

13. Ward EM, Devault KR, Bouras EP, et al. Successful oesophageal pH monitoring with a catheter-free system. Aliment Pharmacol Ther. 2004; 19(4):449-454.

\section{Publish your work in this journal}

Clinical and Experimental Gastroenterology is an international, peerreviewed, open access journal, publishing all aspects of gastroenterology in the clinic and laboratory, including: Pathology, pathophysiology of gastrointestinal disease; Investigation and treatment of gastointes tinal disease; Pharmacology of drugs used in the alimentary tract;
Immunology/genetics/genomics related to gastrointestinal disease. This journal is indexed on CAS. The manuscript management system is completely online and includes a very quick and fair peer-review system. Visit http://www.dovepress.com/testimonials.php to read real quotes from published authors. 